\title{
Performance evaluation of business administration training room in application- oriented universities
}

\author{
Zaijuan $\mathrm{Xu}^{1, *}$ \\ ${ }^{1}$ Guangzhou College of Technology and Business, Department of Business Administration, \\ Guangzhou, China
}

\begin{abstract}
The training room is an important platform for building theory and practice, a link and bridge between universities and society, and an important place for students to improve their practical and practical ability and strengthen the application of knowledge. This paper selected the performance of business administration training rooms of 10 representative application-oriented universities in the Pearl River Delta as a case study, selected the evaluation indexes of input layer and output layer, and used DEA model to analyze the comprehensive efficiency, technical efficiency and scale efficiency of decision-making units. Furthermore, it was proposed to increase the opening and sharing of training rooms, broaden social service channels, optimize teachers, deepen training curriculum reform to improve performance.
\end{abstract}

\section{Introduction}

The report of the 19th CPC National Congress pointed out that "improve the vocational education and training system, deepen the integration of industry and education, schoolenterprise cooperation." In 2018, the Ministry of Education issued Notice on Printing and issuing the implementation Plan for strengthening portfolio Investment and financing support in the Construction of training bases. It was pointed out that: "guide local governments, industrial enterprises and vocational schools, colleges and universities to strengthen cooperation in an all-round way, vigorously strengthen the construction of training platform carriers, and effectively enhance the practical training ability of technical and skilled personnel."

The practical training base in colleges and universities is an important place to cultivate students' practical ability, knowledge application ability and practical ability. It is not only a bridge between theory and practice, but also a link between schools, enterprises and society. The performance of the training base has a direct impact on the quality of teaching and personnel training in colleges and universities, but also related to the development of local economy. Therefore, this paper took the performance of business administration training rooms of 10 representative application-oriented universities in the Pearl River Delta as a

${ }^{*}$ Corresponding author: xzaijuan123@163.com 
case study to explore the current situation and shortcomings of their performance, and then put forward reference countermeasures.

\section{The concept of performance evaluation}

Performance refers to the performance and benefits of various actions taken by organizations or individuals in order to achieve certain goals within a certain period of time. Performance includes benefit, efficiency and effect. According to the production process of products or services, performance can be divided into input performance, result performance and output performance. According to the different evaluation subjects, it can be divided into organizational performance and individual performance.

Evaluation is a process in which the subject understands the performance or ability of the object in a certain aspect. Therefore, evaluation has important reference value for managers' identification, decision-making and prediction.

Performance evaluation refers to the assessment and evaluation of the performance of the evaluation object by using scientific and reasonable evaluation methods and means according to certain standards and evaluation indicators. The elements of performance evaluation include evaluation subject, evaluation goal, evaluation object, evaluation index, evaluation standard and evaluation method. In the process of performance evaluation, attention should be paid to the combination of comprehensive and scientific, the combination of quantitative and qualitative methods, the combination of comparability and maneuverability, and the combination of dynamic evaluation and static evaluation.

\section{Performance evaluation model}

Data Envelopment Analysis ((data envolepment analysis,DEA) was proposed by Charnes et al in 1978 to evaluate the relative effectiveness of decision-making units. The DEA model is used to evaluate the input and output values of the evaluation unit to obtain the efficiency index of the evaluation unit, so as to determine the effectiveness of the technology. DEA uses the mathematical inductive model to get the ratio of multi-unit input to output, so as to get the efficient unit and inefficient unit of the evaluation unit. In the process of evaluation, some units that achieve $100 \%$ efficiency are called relative efficiency units, while other units whose efficiency score is less than $100 \%$ are called inefficiency units. Thus, the evaluation subject can use DEA to compare a group of service units, identify relatively inefficient units, and find out ways to improve efficiency.

The advantage of DEA lies in that it needs fewer samples and has absolute advantages to the evaluation subject of multi-input and multi-output units. There is no need to quantify the quantity when using this model. The determination of weight abandons many subjective factors and aims at the actual data of input and output. The DEA method assumes that there is some kind of relationship between each input and output, but it is not necessary to determine the display expression of this relationship.

\section{1 $\mathrm{C}^{2} \mathrm{R}$ model}

Suppose there are $\mathrm{n}$ comparable decision-making units, each with $\mathrm{m}$ types of inputs and $\mathrm{s}$ types of outputs, and the inputs and outputs of each decision-making unit are represented by the following formula: 


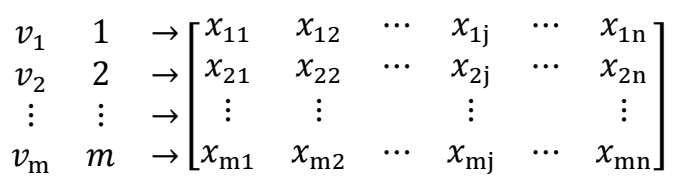

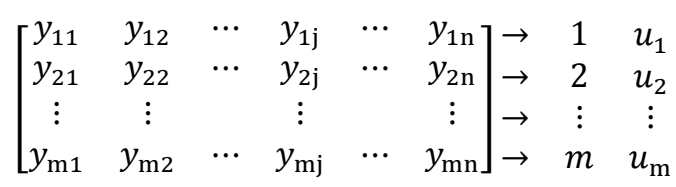

Among them, $x_{\mathrm{ij}}$ is the input of the $i$ kind of $D M U_{\mathrm{J} 0}$, the output of the $r$ kind $y_{\mathrm{rj}}=D M U_{\mathrm{j} 0}$, $y_{\mathrm{rj}}>0 ; v_{\mathrm{i}}$ is a measure of the $I$ kind of input, and $u_{\mathrm{r}}$ is a measure of the $r$ kind of output. If $X_{0}=X_{\mathrm{J} 0}, Y_{0}=Y_{\mathrm{j} 0}$, then the efficiency model for evaluating the $J 0$ decision-making unit is as follows:

$$
\left\{\begin{array}{c}
\max \frac{u^{\mathrm{T}} Y_{0}}{v^{\mathrm{T}} X_{0}}=h_{\mathrm{j} 0} \\
\text { s.t. } \frac{u^{\mathrm{T}} Y_{\mathrm{j}}}{v^{\mathrm{T}} X_{\mathrm{j}}} \leq 1, j=1,2, L, n \\
u \geq 0, v \geq 0
\end{array}\right.
$$

\section{$3.2 \mathrm{BC}^{2}$ model}

The $C^{2} R$ model is an effective evaluation of efficiency on the assumption that the return on scale remains unchanged. In the actual production process of the enterprise, the decisionmaking unit is generally in the state that the scale return is variable, that is, the scale return will decrease or increase. However, due to the influence of the scale factors such as the improper input-output ratio of the DEA decision-making unit itself, the DEA of the decision-making unit will be invalid, and only when the comprehensive efficiency analyzed and calculated by the $\mathrm{C} 2 \mathrm{R}$ model method is decomposed into technical efficiency and scale efficiency, can we find out the scale state of the decision-making unit in a certain situation. Therefore, on this basis, Banker et al further put forward the $\mathrm{BC} 2$ evaluation model. The evaluation model assumes that the scale return of the evaluated decision-making unit is variable, and adds constraints on the basis of the C2R model, so as to obtain the technical efficiency and scale efficiency of the DEA decision-making unit. The specific models are as follows:

$$
\left\{\begin{array}{c}
\sum_{i=1}^{n} \lambda_{\mathrm{i}} X_{\mathrm{i}}=\theta X_{0} \\
\sum_{i=1}^{n} \lambda_{\mathrm{i}} Y_{\mathrm{i}}-S^{-}=Y_{0} \\
\sum_{i=1}^{n} \lambda_{\mathrm{i}}=1, i=1,2, \ldots, n \\
\lambda \geq 0, \quad S^{+} \geq 0, \quad S^{-} \geq 0
\end{array}\right.
$$

If $\theta^{*}=1$, it means that the decision-making unit is weakly DEA efficient. When $\theta *=1$ and satisfies $S^{*+}=0, S^{*+}=0$, this kind of decision-making unit is DEA efficient. 


\section{An empirical analysis on the performance evaluation of business administration training room in application-oriented universities}

\subsection{Determination of evaluation index}

\subsubsection{Determination of decision-making unit}

This paper took the business administration training room of 10 application-oriented universities as a case study, collected the relevant data through research, used the DEA model to analyze the use of the training room of the university, found out the shortcomings, and then put forward constructive suggestions.

\subsubsection{Selection of evaluation index}

The indicators of the performance evaluation of the business administration training room should follow the principles of science, availability and objectivity, and the indicators should be independent and can better reflect the relationship of relative efficiency evaluation. According to the following principles, the input layer is selected as the number of teachers, the area of training venues, the total value of equipment, and annual training projects. The output indicators are: the number of students in school, the number of annual training projects, the number of social training people undertaken annually, and the awards of skills competitions at or above the provincial level in the past three years.

Table 1. Input-output value of business administration training room in application-oriented universities.

\begin{tabular}{|c|c|c|c|c|c|c|c|c|c|c|c|}
\hline & $\begin{array}{l}\text { Decision } \\
\text { package }\end{array}$ & A1 & A 2 & A 3 & A 4 & A 5 & A 6 & A 7 & A 8 & A9 & A 10 \\
\hline \multirow[t]{4}{*}{ Input } & $\begin{array}{l}\text { Number } \\
\text { teachers } \\
\text { (persons) }\end{array}$ & 78 & 98 & 50 & 67 & 58 & 89 & 46 & 71 & 52 & 34 \\
\hline & $\begin{array}{l}\text { Training area } \\
\text { (square meters) }\end{array}$ & 749 & 1277 & 1673 & 2211 & 583 & 637 & 847 & 749 & 849 & 1322 \\
\hline & $\begin{array}{l}\text { Total value of } \\
\text { equipment } \\
(10,000)\end{array}$ & 769 & 839 & 1083 & 862 & 943 & 1277 & 462 & 756 & 931 & 1330 \\
\hline & $\begin{array}{l}\text { Training Years } \\
\text { (item) }\end{array}$ & 27 & 45 & 78 & 44 & 78 & 67 & 78 & 48 & 56 & 74 \\
\hline \multirow[t]{4}{*}{$\begin{array}{l}\text { Out- } \\
\text { put }\end{array}$} & $\begin{array}{l}\text { School } \\
\text { enrollments }\end{array}$ & 1289 & 1678 & 678 & 894 & 932 & 768 & 567 & 1332 & 1289 & 841 \\
\hline & $\begin{array}{l}\text { Number of } \\
\text { annual training } \\
\text { projects }\end{array}$ & 124 & 156 & 324 & 231 & 321 & 145 & 178 & 213 & 245 & 267 \\
\hline & $\begin{array}{l}\text { Annual social } \\
\text { training }\end{array}$ & 3282 & 3241 & 4213 & 2183 & 3212 & 3218 & 4211 & 5213 & 3210 & 1672 \\
\hline & $\begin{array}{l}\text { Awards for } \\
\text { Skills } \\
\text { Competition }\end{array}$ & 34 & 13 & 45 & 22 & 32 & 21 & 42 & 21 & 34 & 36 \\
\hline
\end{tabular}




\subsection{Data analysis}

According to the results of Table 1, the data are analyzed by DEAP2.1 software, and the results are shown in Table 2:

Table 2. Analysis results of input-output performance of application-oriented universities.

\begin{tabular}{|c|c|c|c|c|}
\hline Decision-making Unit & Crste & Vrste & Scale & Status \\
\hline A1 & 1.000 & 1.000 & 1.000 & - \\
\hline A2 & 1.000 & 1.000 & 1.000 & - \\
\hline A3 & 1.000 & 1.000 & 1.000 & - \\
\hline A4 & 0.732 & 1.000 & 1.000 & irs \\
\hline A5 & 1.000 & 1.000 & 1.000 & des \\
\hline A6 & 0.806 & 0.979 & 0.824 & - \\
\hline A7 & 1.000 & 1.000 & 1.000 & - \\
\hline A8 & 1.000 & 0.836 & 1.000 & - \\
\hline A9 & 1.000 & 1.000 & 1.000 & des \\
\hline A10 & 0.923 & 0.989 & 0.976 & \\
\hline
\end{tabular}

\subsubsection{Comprehensive efficiency analysis}

Comprehensive efficiency is the technical efficiency when the benefits of scale are not taken into account. It can be seen from Table 2 that the average comprehensive efficiency of the business administration training room of the ten application-oriented universities was 0.9461, which showed that the overall comprehensive efficiency of the application-oriented universities was higher, and the utilization and allocation of data were more reasonable. They had made outstanding achievements in the quality of personnel training, social services, college competitiveness and so on. But at the same time, we should also see that there were still three application-oriented universities that do not achieve the effectiveness of DEA, among which the comprehensive efficiency values were $0.923,0.806,0.732$, respectively. This showed that the comprehensive efficiency of the three applicationoriented universities still needs to be improved. It should arouse the attention of the relevant departments of the college and improve the performance of the school training room by changing the input.

\subsubsection{Technical efficiency analysis}

Technical efficiency means that the evaluation unit can obtain the maximum output based on the current technical level. As can be seen from Table 2, the technical efficiency of the business administration training room of 7 application-oriented universities was 1 , the efficiency of resource allocation was more reasonable, and the resources invested can be used scientifically and rationally. The other three schools were non-DEA effective institutions, and their comprehensive efficiency was $0.989,0.979$ and 0.836 from high to low. Therefore, it is necessary to rectify and reform the use efficiency of the training room, improve the level of management and service, make a rational allocation of people, money and materials, and improve the quality of personnel training in the training room.

\subsubsection{Scale efficiency analysis}

Scale efficiency refers to the effect of industrial structure on output units through optimal allocation. As can be seen from Table 2, 8 of the 10 application-oriented universities had 
achieved DEA effectiveness, indicating that, on the whole, the scale efficiency of application-oriented universities was better. From the perspective of scale benefits, there were 7 application-oriented colleges and universities for economies of scale unchanged, indicating that the input and output of these schools were scientific and reasonable. DMU6 and DMU10 were decreasing returns of scale, which showed that the business administration training rooms of these two application-oriented universities should appropriately increase investment, expand the scale of training rooms, and introduce highlevel talents. DMU4 was a decline in economies of scale, indicating that this university should appropriately reduce input, rationally allocate existing resources, and improve the level of output.

Table 3 lists the specific values of all relaxation variables for 2 scale efficiency noneffective decision unit inputs and outputs indicators dea. The relaxed variable value in the input index is the quantitative value that the input elements of the decision unit can increase or decrease while the output remains unchanged;

Table 3. Relaxation variable value of input and output index dea efficient decision unit $\left(C^{2} R\right)$.

\begin{tabular}{|c|c|c|c|c|}
\hline & $\mathbf{S}^{-\mathbf{0}}$ & $\mathbf{S}_{\mathbf{2}}{ }^{-0}$ & $\mathbf{S}^{-\mathbf{0}}$ & $\mathbf{S}_{4}{ }^{\mathbf{+ 0}}$ \\
\hline A6 & -13 & -399 & -709 & 37 \\
\hline A10 & -27 & -275 & -512 & 64 \\
\hline
\end{tabular}

\subsubsection{Projection analysis}

In order to solve the problem of scale efficiency, calculate the quantity of input and output index of decision unit to be adjusted, Data Envelopment Analysis (DEA) method can be solved by using projection theory to analyze the non dea effective decision-making units of scale efficiency; Through projection analysis, the decision maker can determine the most reasonable requirement of all input or output indicators, avoid the waste of resources, and provide a reference for scientific decision-making.

As can be seen from Table 4, if decision-making unit 6 wants to become a dea effective unit, the number of teachers will be reduced by 13 in the input index, and the proportion of input reduction will be 14.6 . The area of the training site was reduced by 20.25 . The total value of equipment decreased by 3.09 million, and the proportion of investment decreased by 24.19 . In 2000 , the number of training projects increased by 37 , the increase in the proportion of 55.22. Other dea effective decision-making units perform similar projection analysis.

Table 4. Projection Analysis of Decision Unit 6.

\begin{tabular}{|c|c|c|c|c|}
\hline $\begin{array}{l}\text { Input } \\
\text { indicators }\end{array}$ & $\begin{array}{l}\text { Number of } \\
\text { teachers } \\
\text { (persons) }\end{array}$ & $\begin{array}{l}\text { Training area } \\
\text { (square meters) }\end{array}$ & $\begin{array}{l}\text { Total value } \\
\text { equipment } \\
(\mathbf{1 0 , 0 0 0} \text { yuan) }\end{array}$ & $\begin{array}{l}\text { Year training } \\
\text { project (item) }\end{array}$ \\
\hline $\begin{array}{c}\text { Projection raw } \\
\text { data }\end{array}$ & 89 & 637 & 1277 & 67 \\
\hline $\begin{array}{c}\text { Number } \\
\text { projections }\end{array}$ & 76 & 508 & 968 & 104 \\
\hline $\begin{array}{c}\text { Actual } \\
\text { projection }\end{array}$ & -13 & -129 & -309 & 37 \\
\hline $\begin{array}{c}\text { Percentage } \\
\text { change input }\end{array}$ & $-14.6 \%$ & $-20.25 \%$ & $-24.19 \%$ & $55.22 \%$ \\
\hline
\end{tabular}




\section{Conclusion and suggestion}

From the results of the analysis, we can see that the comprehensive efficiency of $30 \%$ of the 10 application-oriented universities has the problem of low performance. In the future management, non-DEA effective colleges and universities can be made to be DEA effective through the following measures:

The opening and sharing of the training room should be strengthened. For students, the opening hours of the training room should not be limited to normal class hours. When conditions permit, arrange for students to make use of their after-class time to train and study independently. At the same time, we can take all kinds of innovation and entrepreneurship competitions and professional skills competitions as an opportunity to encourage students to make better use of the resources of the training room. For the training room sharing, the business administration major is an interdisciplinary major, which involves computer technology, finance and insurance, accounting customs declaration, ecommerce and so on. Therefore, the business administration training room needs to be integrated and shared with other majors. However, at present, the business administration training room is mainly managed independently by colleges and departments, and there is a lack of interaction with other departments, resulting in the dispersion of school training resources, affecting the overall efficiency of the equipment and increasing the management cost. Therefore, it is suggested that the school should be taken as a whole, and a unified training room management system should be proposed to facilitate the unified allocation of training resources in the school. Based on the principle of professional comprehensive skills and post comprehensive ability training, the interrelated training rooms are integrated to establish a major discipline training center guided by professional groups or subject groups. The training management center uniformly allocates the relevant training resources and carries out comprehensive training to enable students to establish a holistic view and improve their comprehensive ability.

We should broaden the channels of social service and improve the social value of the training room. In order to gradually change the reliance on school funding as the only source of training room construction, we can cooperate with local enterprises and jointly establish training rooms with enterprises. By allowing enterprises to enter the campus, realizing the "order-based" talent training mode, and establishing lieutenant colonels and enterprises, the business administration training room can contribute to serving local enterprises and improve the social value of the training room. At the same time, colleges and universities should make use of their own advantages, make use of the advantages of teachers and talents and training room resources, actively develop enterprise skills training courses, and expand and strengthen social training programs. It can also establish a cooperative relationship with local communities and streets, establish a community training base, and shape it into a place for community life-long education.

The construction of teaching staff should be optimized and the quality of practical training teachers should be improved. All application-oriented colleges and universities should reform the talent introduction system and build a "double-qualified" teacher with both theoretical knowledge and enterprise work experience by means of self-training and talent introduction. We should reform the salary and welfare evaluation system and combine the training of enterprise social personnel, exploring enterprise practice management methods and participating in enterprise internship as teachers' evaluation titles and welfare benefits. At the same time, introducing a group of management talents with practical experience or skilled craftsmen to the school as training instructors in enterprises can give students close access to real management cases and improve their ability to adapt to the society. 
The construction and reform of practical training courses should be deepened. The business administration training room of application-oriented colleges and universities is the base to train high-quality and high-skilled management talents. Colleges and universities should, according to their own advantages and the needs of local enterprises and institutions, closely fit in with major national strategies such as accurate poverty alleviation, healthy China, made in China 2025, and Belt and Road Initiative, integrate curriculum thinking and politics, and create a number of "gold courses" and "high-quality courses". In-depth talent training program: according to the goal of talent training, reform the syllabus, teaching design, teaching plan and teaching schedule, set up courses reasonably, cultivate students' knowledge application ability, innovation ability and practical ability, and improve the quality of personnel training. Deepen the dynamic adjustment mechanism of specialty setting: according to social demand, optimize the professional structure and curriculum system of business administration, combine new industries and new technologies, reform traditional specialties, integrate resources, break the restrictions between disciplines, and establish a professional group of business administration that is highly integrated with practice.

This work was funded jointly by Project of Laboratory Construction and Management of Guangzhou College ofTechnology and Business Guangzhou in 2019(2019-03). Higher Education Teaching Reform Project of Guangzhou College ofTechnology and Business Guangzhou(ZL20191114)

\section{References}

1. N. S. Liang, W. S. Jia, Educational Development Research 17 (2016)

2. G. Cheng, Beijing: intellectual property Publishing House 124 (2015)

3. J. Tang, W. Ding, Experimental Technology and Management 119, 9(2014)

4. Z. J. Li, X. T. Hu, H. J. Cai, Laboratory Research and Exploration 259, 3(2016)

5. W. B. Li, Experimental Teaching and Instruments 110, 13(2016) 